\title{
Book Review: Curriculum Development in Health Professions Education
}

\author{
Hani Salem Mohamed Atwa
}

Faculty of Medicine, Suez Canal University in Egypt and Ibn Sina National College at Saudi Arabia

$\begin{array}{ll}\text { ARTICLE INFO } \\ \text { Received } & : 01 / 12 / 2014 \\ \text { Accepted } & : 07 / 01 / 2015 \\ \text { Published } & : 25 / 03 / 2015\end{array}$

\section{KEYWORD}

Curriculum development Health professions education

\section{ABSTRACT}

Curriculum development is an important area in the field of health professions education. Almost all the books and other materials written in this regard are in English language, which makes it sometimes difficult for non-English speaking curriculum planners to fully understand the jargons and use the steps developing courses and curricula in the health professions education field.

The major objective of the book "Curriculum Development in Health Professions Education”, which is written in Arabic language, is to provide the curriculum developers and implementers in the Arab region with the basic concepts, skills and practices relevant to curriculum development and to stand as a reference for both students and researchers of health professions education in a region suffering great shortage in Arabic literature in this field.

(C) Medical Education Department, School of Medical Sciences, Universiti Sains Malaysia. All rights reserved.

CORRESPONDING AUTHOR: Dr Hani Salem Mohamed Atwa, Address: Faculty of Medicine, Suez Canal University, Ismailia, Egypt. Email: doctorhani2000@yahoo.com

The major objective of the book "Curriculum Development in Health Professions Education”, which is written in Arabic language, is to provide the curriculum developers and implementers in the Arab region with the basic concepts, skills and practices relevant to curriculum development and to stand as a reference for both students and researchers of HPE in a region suffering great shortage in Arabic literature in this field.

This book is written in Arabic language by authors who have an experience in health professions education in the Eastern Mediterranean Region, where the Arabic language is the mother tongue in most of the countries of this region. The authors are primarily physicians and Faculty in the first medical education department in the first innovative, community-based medical school in Egypt and the region which is the Suez Canal University Medical School founded 1978.
Although the authors state that they intend to reach a diverse audience that includes teachers, administrators and funders, the book is probably best targeted for health professions educators whether in the academic or service provision training centers.

The skeleton of book is divided into three main sections. The first section discusses the fundamentals of educational design as well as the different approaches and strategies of curriculum development in HPE. In the second section, which includes multiple chapters, the authors recommended four-steps for curriculum development in HPE. In the third section, a brief Arabic glossary of the most common HPE jargons is included.

The recommended four steps for curriculum development in HPE through this book are:

1. Educational needs assessment. 
2. Determination of four core curriculum elements (defining objectives, content selection and organization, identification of relevant instructional methods and planning for assessment).

3. Curriculum implementation.

4. Curriculum evaluation.

Throughout the book there are practical realworld examples from a variety of health disciplines. The authors have attempted to contextualize and reflect their ideas on the Arab world that has very characteristic social and cultural perspectives.

The authors' management of the subject matter is comprehensive. The multiple examples and illustrations are useful for explaining the content of the text. The information is up-to-date with references to current peer-reviewed articles, research papers and books in health professions education.

In the foreword of the book, Dr. Hussein $\mathrm{Al}$ Gezairy, the Regional Director of the EMRO/WHO, describes the book as a "guidebook" for anyone involved in health profession education.

Chapter 3 (Curriculum Evaluation) is particularly helpful for educators and curriculum developers who wish to evaluate their curriculum development initiatives. The section on students' assessment also includes a brief discussion of the issues associated with selection and utilization of the different assessment methods and tools.

The book "Curriculum Development in Health Professions Education" is well-written and easy to read. The organization of the book into three sections helps the reader navigate through the content. The information is logically presented, beginning with the definitions and concepts related to curriculum development in health professions education, followed by a discussion of practical fours steps for curriculum development and ending with an important glossary that Arabize for the first time a wide array of health profession education jargons.
In spite of the novelty of addressing this topic in the Arabic language and the big number of new health professions education jargons in Arabic, the book reads in a very coherent manner.

If curriculum developers, educators and administrators are looking for a "how-to" practical book, this will satisfy their search and meet their needs and expectations.

\section{Further reading}

Abdel Aziz A, Hassan N. Curriculum Development in Health Professions Education. EMRO/WHO Publications. Cairo, Egypt (2012), 139 pp., ISBN 978-9290-2184-94. Soft-cover. 